\title{
Perceptions of Chinese students in an Australian university: are we meeting their needs?
}

\author{
Carmela Briguglio \& Robina Smith \\ Curtin University \\ C.briguglio@curtin.edu.au
}

\begin{abstract}
This short-term longitudinal study sought to identify the issues faced by a group of international Chinese students undertaking university study in an Australian university. While the focus was on educational issues, socio-cultural and personal factors were also examined in an attempt to identify the sorts of strategies students used in settling into a new socio-cultural and educational context. Interviews undertaken at the beginning and end of the first semester of study indicate a range of issues that are supported by previous studies. What has not previously been highlighted, however, is the emphasis on speaking and listening skills which students reported they needed to improve. Lack of proficiency in these areas was seen by students as hampering their active participation in class, leading to lack of confidence in approaching Australian students, and resulting in their inability to benefit from the "Australian experience". Many existing academic support structures in Australian universities tend to emphasise support with written and study skills. While this is important because of the direct impact on assessment, it is perhaps now opportune to place some emphasis on developing strategies and programs that will support the development of students' speaking and listening skills, with a focus on intercultural communication.
\end{abstract}

\section{Keywords}

International education; Chinese learners; needs of international students; international student support; internationalisation.

\section{Introduction}

Much research with a focus on the needs of international students and the support they require has been, and continues to be, undertaken in Australian universities (for example, Mullins et al., 1995; Ballard \& Clanchy, 1997; Pantelidis, 1999; Briguglio, 2000; Ramburuth, 2001; Lawrence, 2005; Ransom, Larcombe \& Baik, 2005) as well as internationally (Sovic, 2008). There have, however, been fewer studies focussed on the needs of particular sub-groups, although Chinese students, who since 2004 have become the largest cohort of international students in Australia, are beginning to draw more attention (see, for example, Cooper, 2004; Le \& Shi, 2006; Wang \& Shan, 2007; Zhang, 2010). The numbers of Chinese students in Australia have increased in recent years to the point where China now ranks as the number one source country for Australian international students, with a total of 118,301 students in 2009. Of these, some $42 \%$ were enrolled in higher education in 2009 (DEEWR, 2010). The University where this study is located is among the four largest providers of international education in Australia, with international students comprising almost $28 \%$ of all onshore enrolments (Curtin University, 2010). In 2008, there were almost 9,757 international onshore students at Curtin, with this number increasing to 10,327 in 2009. Chinese students at Curtin University numbered 2,372 in 2008 and increased to 2,716 in 2009. They are by far the largest group of international students at Curtin ahead of those from Malaysia (1,679 in 2009) and Indonesia (826 in 2009) and the largest group of international students in the Curtin Business School. 
This study examines the first semester experience in an Australian university of a group of Chinese students from articulation programs with two universities in China. Their experience is discussed within the broader context of international students in Australia. The study uses an ethnographic approach based on qualitative data gathering techniques, including semi-structured interviews. Major socio-cultural and linguistic issues are identified and examined, with the aim of providing recommendations for strategies that will assist Chinese students in making a smoother transition to Australian universities and allow them to gain the greatest benefit from the Australian experience. More specifically, this study aimed to:

- indentify the problems that a group of international Chinese students typically experience in their first semester in an Australian university;

- examine the coping strategies that students develop to gain the most from their educational experience;

- examine how significantly English language skills impact on students' participation in their studies and on the Australian experience.

\section{Background}

International education in Australia has been a success story since its small beginnings in the mid 1980s, to the point that Australia now ranks as the third most popular English speaking study destination in the world and the fifth most popular overall (DEEWR, 2010). However, in recent times competition has become more intense and students are demanding not only quality course, but also quality infrastructure and support services (Chapman \& Pyvis, 2006). According to Marginson (2006) Australia is largely engaged in two types of cross-border education: one that sees students from emerging nations, particularly in the Asian region, entering English-speaking nations; and the other conducted in offshore branch campuses or online. Marginson (2006, p. 18) states that:

Foreign students invest in global positional goods that facilitate mobility and changing identity. Many graduates enter mobile occupations such as business, IT and scientific research where English language skills are used. The positional goods include not just foreign degrees themselves but foreign language, the experience of living abroad and access to migration. [author's emphasis]

While Australian universities (and the Australian government) have in place a number of measures that provide a strong guarantee of the quality of the degrees they offer, our study shows that there is perhaps room for improvement in regard to the provision of English language support and the living abroad experience.

There has been awareness and concern for the support needs of international students since international education programs began to be implemented by Australian universities in the 1980s. Research on the support necessary to ease the transition of such students into the Australian experience has addressed a host of social, cultural and adaptation issues, and the support structures and services provided by universities (see, for example, Mullins et al., 1995). Such aspects have been discussed and elaborated at many Australian conferences and platforms, including tertiary education, language and international education conferences.

The English language question and academic literacy issues have been of major concern both within academe, and more broadly, amongst employer groups. The support provided by universities has moved through a series of different philosophical approaches. It began with a focus on English language support, at first perhaps conceived in a remedial light, and gradually developed to include consideration of a number of related socio-cultural factors (Ballard \& Clanchy, 1997; Watkins \& 
Biggs, 1996) and moving towards an inclusive curriculum approach in teaching and learning (Hutchison, Morrigan \& Mappin, 1997; Bonanno \& Jones, 1996; Lawrence, 2005). More recent thinking promotes the embedding of academic literacy skills and support through all disciplines across the curriculum (Crosling \& Wilson, 2005; Baik \& Greig, 2009). There is still much debate about the English language question, and the perceived low level of English language proficiency of international graduates from Australian universities has drawn some criticism (Birrell, 2006; Bretag, 2007).

In the past, the needs of Chinese students have tended to be included in studies on 'international students', though in some cases (Watkins \& Biggs, 1996) differences relating to Chinese or 'Confucian-heritage' students have been discussed in some detail. More recently there has been a stronger focus on the learning style of Chinese learners, with some (Le \& Shi, 2006) suggesting that Chinese students from different ethnicities (eg from mainland China, Malaysia, Singapore and Hong Kong) may display differences. Chinese or Confucian-heritage students have, in the past, tended to be portrayed as 'passive learners' who prefer to be given information in teacher-directed and teacher-dominated classes, and who memorise by rote, using 'surface' instead of 'deep' approaches (Biggs, 1996) to learning. All of these assumptions about the learning style of Chinese students have been challenged in more recent times (Biggs, 1996; Chalmers \& Volet, 1997; Kennedy, 2002; Cooper, 2004). As will be discussed below, our study has found that Chinese students identify fairly quickly any adjustments they may need to make in order to be successful in their studies and, understanding that different approaches may be required in Australia, they certainly make attempts to adapt, in some cases preferring the 'new' teaching and learning approaches they are experiencing.

\section{Method}

An ethnographic approach using largely qualitative data-gathering techniques was used for this short-term longitudinal study. Blomberg et al (1993) and Le Compte and Schensul (1999) indicate that an ethnographic approach includes, among other things: research carried out in a natural setting, situated within the larger context or 'bigger picture', involving objective observation of people and interactions, and with a bias towards understanding things from the informants' perspective. The researchers drew on their knowledge of the 'bigger picture' and on previous studies they have undertaken with international students (Briguglio 2000; Briguglio \& Howe 2005) to design this study.

\section{The student cohort}

The students who are the subject of this study all come from two Chinese universities which have a special 'articulation' arrangement with Curtin University. Students undertake the equivalent of the first two years of their course in China and then come to the main campus in Western Australia to complete the last year of their studies. All students are enrolled with the School of Accounting and graduate as Accounting majors. This arrangement has been operating for some five years, and this study was undertaken in 2008, the third year of the program's operation. In that year there was a particularly large cohort (49) from one of the transnational partner institutions, from which some 16 of the students interviewed originated. This means that there was a sizeable group of Chinese students who already knew each other and who could to some extent form a support network for each other. It is also important to keep in mind that although these students could be considered to be 'third year' students, they were in fact in their first year on an Australian campus, and therefore subject to the sorts of well documented problems faced by first year students in Australian universities (McInnis \& James, 1995; Krause, 2003; Krause et al., 2005). Moreover, for almost all students this was their first time away from home. 
Students generally arrive one week before the commencement of semester so their accommodation and living arrangements can be finalised. The first week included a brief half-day orientation program. During the orientation, students were informed about this study and asked to volunteer if interested. A number of students were keen to do this and some 25 students registered. Eventually, 20 students took part in the first interview and 17 in the final follow-up interview. All but two of the 20 were females and aged between 20 and 21 years of age. The other two were males of the same age. Students were assured of confidentially in all aspects of the project, for which normal University ethics clearance had been obtained.

\section{Data gathering instruments}

Data were gathered through: two semi-structured interviews, one 'on-arrival', undertaken in the second or third week on campus, and one 'end of semester' interview undertaken four months later; and two short writing tasks, undertaken at the same time as the two interviews. Student semesterweighted averages (that is, the average of the four units of study undertaken during semester) were also accessed to monitor student academic performance, and to examine correlation between what students told us of their experience during the semester and their academic achievements.

We were concerned to obtain the student voice and to allow students to freely express what they felt and what they had experienced. To this end, interview questions were open-ended. Questions in the first interview addressed the following areas: background information related particularly to where students had learned English and how well prepared they felt linguistically; what they knew about Curtin university before arriving in Australia; what differences they saw between Chinese and Australian learning environments; any difficulties they had experienced since arriving; the people from whom they had gained assistance or support; any cultural differences they had noticed; and their first impressions of 'Australian' students and staff. Questions in the second interview addressed: how well students felt they had progressed in their first semester in Australia and whether the experience had been what they had expected; whether they had experienced any problems and people from whom they had gained assistance; whether they had met any Australian students and what they had learned about Australian people and culture; whether their linguistic skills had improved and in what ways; and how they had enjoyed their Australian experience. Interviews were undertaken by one of the researchers and lasted for between 20 and 50 minutes, with the second interview in November generally lasting longer than the first interview in August. All interviews were recorded, transcribed and analysed.

The writing task was undertaken immediately after the completion of the interview and students were told they had about 20 minutes to complete it, and longer if they needed more time. The writing task was administered for two reasons: first, it was considered that it might allow students to put in writing things they might not want to express directly to the interviewer; and second, it would provide an idea of students' written linguistic proficiency. Topics for the writing task were deliberately open-ended and did not require any specialist business knowledge. The first writing task asked students to address one of the following topics: "What difficulties might you face while studying for your degree at Curtin University?" or "Describe your first week in Australia." The second writing task asked students to address the topic "Tell us of your overall impression of your study at Curtin during your first semester". Similar questions had been used in writing tasks for previous pilot studies with international students and had produced useful data (Briguglio \& Howe, 2006; Briguglio, 2007)

\section{Data analysis}

Analysis of data from interviews and from the writing task is based on a domain analysis process to identify major themes and issues (Atkinson \& Abu El Haj, 1996). Atkinson \& Abu El Haj describe a four step process that can serve in the analysis of qualitative data, including: identification of 
domains (major categories of data); construction of a taxonomy of sub-categories under each domain; analysis and elaboration of what participants have said about each of the sub-categories; and, finally, building up the overall bigger picture by examining the relationships between data in sub-categories and domains.

The study draws on data obtained from the interviews and the writing task. These instruments had been pilot-tested in previous studies with students who shared similar characteristics as this cohort. Interview questions were also pre-tested with a small sample, in order to ensure their suitability.

We thought it important in this study for the student voice to be heard. We have therefore quoted, where appropriate, both from interviews and from the written tasks, to lend weight to our discussion and conclusions. However, in order to assist the flow of writing, we have omitted pauses and repetitions or any other redundant expressions which are normal in spoken language. Also, in order to safeguard privacy, a number, and not the student name, is used to refer to a particular student.

\section{Students' on-arrival impressions and issues}

Data gathered for this study are discussed under four broad identified domains, as follows:

- adaptation issues

- differences in learning contexts and learning styles

- English language issues, and

- interaction with Australian students, staff and the broader community.

Data from the first interview, undertaken at the beginning of students' first semester in Australia, will be discussed in the first instance, since this provides us with students' "on-arrival" impressions and feelings. Data from the second interview, undertaken four months later (at the end of semester), is then be discussed, allowing a comparison with first impressions, and detailing developments and changes that have occurred.

\section{Early adaptation issues}

Students were asked a range of questions about their early impressions and experiences. It should be remembered that at this stage students had experienced only one or two weeks on campus. Early adaptation issues have been categorised into the four following areas: preparation prior to arrival; everyday living issues; perception of self and feelings of self-efficacy; and early sources of help and support.

Students reported that they had felt reasonably well-prepared before coming to Curtin. Several had gained information from friends and acquaintances who had already studied at Curtin while others had accessed online information. However, one or two complained of not having enough information about Curtin before their arrival. Although they had thought that linguistically they were well-prepared before coming here, a number expressed their dismay after hearing English spoken at what, invariably, was perceived as a fast rate, and experiencing difficulty with understanding. This is, of course, a fairly typical reaction from ESL speakers on being thrown into a 'native speaker' environment. Consequently, quite a number said they now felt under-prepared and were worried about their inability to speak and understand Australian English. Comments such as the following are typical:

I used to study well in China in English but by coming here I found it was difficult to communicate with Australians. I think I need more practice in oral English. (10)

Listening [is most difficult]- the people here speak too fast so I have to try my best to catch up with them (6) 
Everyday living issues were, understandably, of some concern to student in this on arrival period. For many of these students this was their first time away from home and outside China. Students were puzzled, amused and curious about what they saw as some cultural surface differences relating to public transport (very slow and rare), shopping (difficulty understanding labels and very expensive items), scarcity of people on the streets at night (for some, eerily quiet) and banking requirements (difficulty of opening up an account). All of them expressed some concern about having to tackle such tasks as cooking, which most had never had to do for themselves before.

When I came here I feel homesick. But gradually I think I must be mature and look after myself. And before I didn't cook but when I came here I had to learn how to cook, to buy vegetables, to buy meat. I find it difficult but it's forced me to be mature, to grow up (13)

What was particularly striking during these first interviews, however, was the sense of determination and self-efficacy displayed by students. Bandura $(1997$, p. 2) defines self-efficacy as "beliefs in one's capability to organise and execute the courses of action required to manage prospective situations". Alongside feelings of concern, some minor anxiety and some hesitancy, students also displayed determination and a strong desire to succeed. Quite a number of students reported that they were experiencing some homesickness, a loss of confidence and a little dismay at not understanding some of what was being said in class. One student who experienced a serious bout of homesickness early in the piece wrote:

[The first week] was really a tough week for me in Australia. I came to a totally different country and far away from my family, my friends and everything I used to be familiar with. I remember clearly the first day when I arrived here; I just went into my room, sat down and cried out of control [...] I had a terrible dinner in the evening... noodles without salt. (10)

However, in almost all cases, any such feelings were backed up by expressions indicating students were going to do their utmost to ensure they succeeded in their studies.

I think [at first] it will be very difficult, but after some time I will adapt to the new environment. I don't think it will be a difficult thing.(1)

I have confidence. No, I don't have much confidence when I first come here to speak with others. But the only way I can improve my English is to practice with others. So I tell myself I should have the confidence and we should believe in ourselves. (12)

In regard to issues such as the above, students were asked where or to whom they would go for support. Even when the question was phrased so that it referred specifically to University support ("Who have been the most helpful people for you when you started at Curtin [which office, service or individual]?") the answer was invariably "my friends" or "my classmates". Students overwhelmingly referred to gaining support from Chinese friends and acquaintances, including by electronic means (for example, a Chinese friend in Sydney). This might be the case for this particular cohort which, as indicated above, had quite large numbers coming from the same institutions. When pressed again for information about anyone apart from friends who had been of assistance, students indicated people who had helped them with lost keys, directions and library processes, and some mentioned tutors or staff from the Communication Skills Centre. The impression is that students would not automatically think of going to seek help from a University service, just because it is there, available and even free. This attitude had changed somewhat by the end of semester, as will be reported later. 


\section{First perceptions of differences in learning contexts and learning styles}

Students were asked what differences they noticed between the teaching and learning context and approaches in Australia compared to what they were used to in their previous university in China. Students' early impressions were that the physical environment is pleasant with good equipment, facilities and services but accompanied by the personal stress some were experiencing in relation to their lack of fluency in English and becoming acquainted with new people (staff and classmates) and new expectations. They reported that the quiet after $6.00 \mathrm{pm}$ here in Australia was good because there was not much to do socially and therefore it was more conducive to study (!).

One day when I called my father there was silence at 6.00 o'clock and there's nobody in the streets. But in China there is a lot of people around in the street all the time. In China we have other things to do, for example TV, movies, to eat in a luxury restaurant and dance, singing and shopping: so this is a good place to study. (16)

They reported there was more freedom here to select subjects and optional units. In China students had been told what units they would study and there was no choice. There were no tutorials in China and classes tended to be fairly large so there was not really much opportunity for discussion. Generally students said they spent much more time in class in China, but less having to work on their own outside of class. The system in China, they felt, was more teacher-directed. They also thought there was more emphasis on reading and writing in China, whereas here in class students were expected to speak a lot more. This gave them the impression that people here are "more open and more passionate". In China there were not many assignments as such and the system was more geared to passing exams, a system which was easier, from their point of view.

Here we need to discuss in class, but in China we only listen to what the teacher taught us, not to discuss in class (13)

In China the teacher will give me answers. It is the standard. But in Curtin, I think the professor just gives me a way of thinking. I have to solve the questions by myself (3)

Based on their early impressions, interviewees felt that locally students were expected to learn "more independently" and some students said they found it difficult to handle the "free time", that is, time when they were not in class and which they had to utilise to study on their own. In any case, most said they would not study on their own, as such, but would always study with a group of friends. Going to the library or the laboratory on their own was something they would be unlikely to do.

Maybe in China the tutor will just tell you how to do something ... but here we have to spend a lot of time studying by ourselves. And also in China, although the tutors speak English, if we can't understand we can explain in Chinese, but here not so. (9)

Even though they noticed that there was more talk in class here than there would be back in China, many reported that they had had little opportunity to speak English in the Australian classroom, or indeed out of class, a situation which they hoped to improve in the future. They were anxious because they felt they lacked particularly the interpersonal communication skills in English which would allow them to take a more active part in their learning experience and to meet local students.

Sometimes it's difficult, especially in a tutorial class. I find it so difficult because my English is not good enough [...]. Sometimes I want to speak but they speak so fast I can't catch up. (8) 


\section{On-arrival English language issues}

All students interviewed had learned English at school, most beginning in middle school and some in primary school. Nunan (2003) reports that the age at which English is a compulsory subject has shifted down in recent years in China, as in most other countries in the Asia Pacific region. Interviewees reported that the English they had learned in China focussed on reading and writing and only minimally on listening and speaking. This emphasis on reading and writing skills is supported by a study carried out by Sawir (2005). Nunan (2003) also indicates that the amount of English language exposure and the preparation of teachers of English in China and other in Asia Pacific countries are probably insufficient to lead to students gaining much fluency in interpersonal communication skills. Interviewees reported that they had considered themselves to be wellprepared linguistically, until they came here and had difficulty understanding and communicating.

Sometimes I maybe have some problems with the speaking [...] I have the feelings but I cannot find the right words to describe my feelings. (4)

In regard to English language issues, almost all students expressed that they were having difficulty understanding the English of students and staff, who were generally perceived as speaking very fast - the latter a fairly common reaction for English as a second language (ESL) learners when first interacting with native speakers. In class they reported experiencing problems particularly with understanding more "language rich" subjects, such as those in the Business Law, but also some difficulties with discipline-specific language in some Accounting units. In everyday interaction they were aware that they may not understand local students because of local idiom and slang, as well as perceived speed of native speakers' language and possible socio-cultural issues. As well, a few reported not understanding English as spoken by other international students.

Sometimes I think it's my problem because of the level of my English and sometimes I think maybe there are also conflicts of culture when we can't understand their meaning specifically.

In regard to lectures, students reported that they probably understood between $60 \%$ and $70 \%$ of what was being said (a couple even less than this). They found it particularly difficult to concentrate on what the lecturer was saying at the same time as trying to read what was on slides. The problems of international ESL students in lectures have been well-documented by Mulligan \& Kirkpatrick (2000). Students said they tried to do one or the other, because juggling both was too difficult.

I think lecturers are a bit hard [to understand] because when I watch those slides and those words I don't know, I understand what she is talking about, but when I listen to what she is talking about I can't understand the words on the screen. So it's hard for me to balance. (6)

When asked which macro-skills they particularly needed to improve, overwhelmingly the response was speaking and listening.

The most important [skill] is listening. I think listening is the most important because if you want to connect with others, you should listen to what he or she is saying. And second is speaking - we come abroad so we should make a conversation with others. (12)

In spite of the above issues, this group of students demonstrated that they were all keen to succeed in their studies and tried to help themselves in the following ways. Almost all indicated that they did pre-lecture reading, in an attempt to familiarise themselves with the content and with any special terms before the lecture. Some had already approached tutors for assistance. Others had attended 
the Communication Skills Centre workshops or had approached Centre staff for individual appointments. Still others had sought help from library staff. Students seemed very aware of the need to improve their English language proficiency quickly and determined to do something about it.

I think the important thing to living here is to be independent.... not to be homesick and to try to learn English as much as you can .... as well as you can. (1)

\section{Early interaction with Australian students, staff and the broader community}

Since these first interviews took place in the second or third week of semester, it might be understandable that students had not yet had the opportunity to meet too many local students, staff and members of the wider community. Unfortunately, as will be elaborated in the next section, things did not improve markedly in this area during the semester. Students certainly have the hope and desire to meet Australians. As one student wrote:

I would like to know more about Australia and the social life. I hope I can experience more than studying. (6)

Early student perceptions of local staff were that they are very "friendly". Students reported that they seemed to smile more than Chinese teachers, that they were approachable and "helpful", that they seemed "patient" and "professional". Some also reported that staff here seemed to dress more formally than in China. Students reported that they found tutors particularly approachable and helpful.

I think the tutors and lecturers in Australia are very kind because sometimes I cannot understand some part of the accounting and they try to teach me a lot after class, so I am very thankful. (23)

Oh I think they [Australian staff] are very good because they are kind and consider our condition to help us and ... adjust their ways of teaching or something. (14)

Australian students seemed to be "confident", "friendly", "active" and "very independent". Most students reported that they had not met any Australian students, except to see them in class and occasionally in University housing. On such occasions, Australian boys were not very talkative although they generally greeted the Chinese students. Australian boys in university housing seemed to be more bent on having parties and drinking and were, perhaps, "too shy" to mix. These and similar perceptions, which may be quite superficial, were nevertheless repeated by a number of students interviewed.

Hmm...Australian students. In my dorm there are three handsome boys who are Australian but we can't speak more because all day they will play games and drink some beer and they look a little shy. We are also a little shy so... maybe we don't communicate very much. (12)

So far as meeting Australians outside the university campus, students reported that they had approached strangers for help with labels in supermarkets and occasionally to ask for directions, but there was no other contact apart from this. Students' impression of Australia and Australians in the first few weeks was that life here seemed more relaxed, more independent (separate from friends and family) and that Australians seemed more outgoing than Chinese.

I think Chinese are quite reserved and Australian people are very outgoing and they just speak a lot most of the time. (10) 


\section{Perceptions at the end of semester}

In the second interview students were generally a little more articulate and all interviews did in fact last longer. On the whole students had settled in fairly comfortably and were enjoying their experience here. Almost all students had a part-time job, many in fast food outlets either locally or in other suburbs. Although there may well have been financial reasons for students to work, these were not reported, but almost all mentioned that the job gave them a chance to interact with Australians and to improve their English language skills.

\section{Adaptation issues}

Most students reported they had learned many life skills, such as looking after their finances, which they had not previously been able to develop in China, this being their first experience away from home. Many said they could now cook and were enjoying the experience and were indeed proud of their achievements in this area. Although several found the Perth lifestyle somewhat quiet, they said this was good for study. They had learned how to regulate their time for private study and made full use of facilities and the Business School's learning management system, Blackboard.

I think it [studying in Australia] has taught me about living by myself, living independently and those things, I think they are very important (6)

In an effort to meet locals, some had joined church groups, which they were enjoying. They still relied on classmates and roommates for support, particularly for personal matters, but in regard to study issues, they went to tutors a great deal more. All students sounded more confident and selfassured. Several said they had really begun to enjoy the independent living experience (that is, being away from home) although they had occasional twinges of homesickness. So far as their studies were concerned, they were still determined to succeed and felt that had done reasonably well.

I found it's a little hard, but generally I can handle it. Maybe I can't get distinctions, but maybe I can pass all my units [...] I have learned a lot from these courses. (7)

\section{Differences in learning contexts and learning styles}

Students reported that they were becoming accustomed to the local learning context and that they in fact preferred the local style of teaching, which they felt made them more independent learners. They enjoyed the practice of having assignments and projects here, which they said could be "exciting" and taught them "more deeply" than just cramming for exams, as they had done previously in China.

Yes, I think now I [feel better prepared for study], because in our country always the teacher tells you what you should do and you just follow...But now, it's more like self-study and we study more inside..... what we want to learn and not just what the teacher tells you. So I think this is good for me. (23)

In regard to their study habits, students reported that they still tried to prepare before lectures, while several said that they recorded lectures and then listened to them again, while others reported reviewing lecture notes. Many said they prepared for tutorials as well. The overall impression was that students spent many hours studying, probably more than their local counterparts.

Study life is..it's a little busy.. Because we have a lot of exercises and we do the exercises again and again to prepare for the finale exam. It's the biggest difference from what we do in China. 
Normally we just ask the teacher for a hint or just study the textbooks and remember something important and obvious. It's much easier to pass exams in China. (5)

\section{English language issues}

English language issues continued to be of major importance and concern to these students. While some felt they had improved their listening skills and could now understand their lecturers and tutors more easily, almost all complained of not feeling they had improved their speaking skills to any significant degree.

I hoped to improve my English here, but I find there is very little chance for me to speak English fluently or communicate with others because I live with my friends and they are all Chinese except the study in classes, so most of the time I am sitting with my friends and we all speak Chinese (14)

Some students felt that their lack of proficiency in English might be affecting their marks, in spite of the extra effort they were expending in preparing for classes:

I prepare well before class but still say little in the classroom and just get an average participation mark. All of this proves that I need to improve my English language skills. (7)

Although they now felt somewhat better prepared to interact with people, interaction with Australian students, staff and the broader community seemed elusive, and they still felt their speaking skills would not be sufficient.

Here in Australia people talk different. Like in uni people talk more clearly and I think I understand. But if, like now, I work in a kitchen and sometimes they talk different from uni ...it's hard to understand them. (21)

\section{Interaction with staff, students and the broader community}

Almost all students reported going to seek assistance from tutors with any questions relating to their course, while quite a number had arranged individual appointments with staff from the Communication Skills Centre to review their assignments before submission. The interaction with staff, particularly tutors, had increased significantly from the time of the first interview, four months previously. Students also seemed not to have too much hesitation about going to see tutors and lecturers to seek clarification during allotted consultation times.

I attended Communication Skills Centre workshops a lot and when I have questions with my study I will ask the tutors or lecturers for help. (11)

Without exception, there was high praise for staff, both lecturers and tutors, and for administrative staff, in some cases. While students would perhaps be more likely to avoid criticism of staff members in an interview situation, they might have done so in the written tasks. However, overwhelmingly, there were positive comments about staff - the only reservation being that sometimes staff were hard to understand in class. For the rest comments such as the following were quite common:

The teachers are very responsible and they give me a lot of help (2)

The tutors were great and professional. They can explain everything in detail and [make it] understandable (10) 
While interactions with staff increased over the semester, there was no reported difference in their interactions with Australian students. Interviewees reported that they had met almost no Australian students, except those they saw in class. However, as one student put it:

It's hard [to meet Australian students] because we don't have too much time that we can talk [in class]. In fact the white students always talk with the white students and our students we always talk to each other (6).

Chinese students had met other students from all over the world, but not Australians. Again, the comments about male Australian students in university residences indicated they were perceived as being more interested in socialising ("they are party animals") while Australian girls appeared somewhat aloof to these Chinse students.

I think communication is still a big problem because I have not [spent] much time to talk with other local people [...] and maybe we can talk with other international students such as Iranians and Malaysians, but the local student we didn't have much contact with.[..] I think they are totally different from us, because they are very cool and they don't like to talk with us.

(6)

On the whole, students thought Australia was beautiful, very quiet, with a relaxed and easygoing lifestyle. Students thought that Australians were fairly "optimistic", "friendly" and "nature lovers" who enjoyed an easier lifestyle than do people in China. However, all these observations seemed to come very much from the outside and could be considered superficial. No-one reported having formed any friendships with locals or having been to an Australian home or family event.

We have not met any [Australian students]. Just in class we just speak a little, but after class we have no contact with each other (12)

\section{Discussion and recommendations}

This cohort of Chinese students on the whole navigated their way through the first semester in a foreign country with some success, and ended up by having a positive (thought not always easy) experience. So far as their academic results are concerned, all students passed all four units of study undertaken, in some cases very comfortably. Most students scored lowest in the unit Law (Business Organisations) which might be considered the most "language rich" unit alongside three other accounting units undertaken. Surprisingly, the student who scored highest overall was the one who experienced a quite serious illness during the semester. On the other hand, she displayed enormous determination from the beginning.

I find it difficult to adapt [to the teaching and learning environment] but I believe I can try to learn and read books, listening every day. I think I can improve. (13)

There would seem little doubt that by the end of semester, students felt more confident, independent and able to take care of themselves. Our study would seem to support the findings of Lewthwaite (1996) that although international students experience some adaptation problems, they may not experience high levels of stress. This was the case with our cohort, at least insofar as could be gauged from what they reported. However, care must be taken not to assume that this would be the case for other international students. This cohort did not report serious levels of loneliness after the initial on-arrival period, perhaps buoyed by the fact that there was a sizeable group of 49 students from the one institution, and a smaller number from the other, so that all students had friends or acquaintances on whom they could depend for support. 
Care should also be taken to not under-estimate the effort that these students expended in order to achieve academic success. The fact that at the beginning of semester they do not understand a sizeable proportion of what is happening in class means that they are in fact missing out on the broader "introductory" aspects of their units of study - important information which contextualises the unit, providing an outline and the broad directions. So the fact that by the end of semester, some of these students like the "more independent' style of learning does not mean that they take to it easily. Academic staff could perhaps do more in class to prepare all students for participation in class discussion and interaction.

Students were able to reflect on their experience and draw some of their own conclusions about what they had done well and what they could perhaps do better. Many of them said they now felt better prepared for study in Australia and quite a number were planning to go on to undertake study for a Masters degree. They also felt that they had matured by coming through a fairly difficult experience and learning from it to become more independent.

This semester I have experienced a very different study process compared with what I did in my motherland [...] I think this is a vital and excellent study experience, and I enjoyed it (4)

Like many young people, irrespective of background, these students were also excited by their exploration of the world. One student reported her first semester had been "interesting, amazing, exciting!" Another wrote:

In one word, I have got so many beautiful memories this semester at Curtin!(3)

It was notable through both interviews that these students had very high levels of self-efficacy and a belief in their ability to be successful in their studies. They were quite aware of the immense effort they would need to expend, but at no point did they indicate they had experienced any feelings of giving up their studies and returning home. Even the one girl who had had suffered a serious illness thought about returning home only briefly. She recovered quickly (in 2 weeks) and then made up the time lost in classes to achieve very good results. It is also remarkable that all these students, almost without exception, misunderstood the question we asked them about whether they had thought at any point of giving up and going back home. In the first instance, most students understood us to be asking about whether they were intending to go home during the intersemester break. The interviewer had to repeat the question several times, and all students, without fail, indicated they would not think of giving up but would simply study harder if necessary. Failure was simply not an option.

I think I have difficulties but I should deal with the difficulties by myself. I cannot [...] my parents will be disappointed in me. I should work hard and deal with difficulties and I cannot, I cannot give up. (4)

One question at the end of the second interview where students were asked what advice they would give to incoming new students from China drew very interesting responses and shed much light on the things they consider most important. Almost all students said they would advise other Chinese students to be better prepared with their English language skills, particularly listening and speaking; that students need to be disposed to being more active and independent learners when they come here; and that they should be prepared to communicate with people from different cultural and religious backgrounds. Most importantly, several said that student should forcibly separate themselves from their Chinese friends in order to mix more with other students and therefore improve their English language skills. This may, however, be wishful thinking, since the valuable (moral and psychological) support of their friends was stressed time and again by students 
themselves, particularly in the on-arrival period. Staff could, however, deliberately structure class activities so that international students are forced to mix with local students.

Students were pleased that they had learned something about other people and cultures. However, questions relating to what they had learned specifically about Australian culture indicated fairly superficial observations and very little real contact with Australians both inside the University and outside.

All in all, therefore, although students are reasonably happy with their Australian experience, there seem to be two major areas where the University could help Chinese students to gain greater benefit from their study abroad experience:

- developing English language skills (particularly speaking and listening) both for interpersonal communication and for academic literacy purposes; and

- meeting and interacting with Australian students, in particular, and the Australian community more broadly.

The two issues are, of course, closely related and interwoven. If students do indeed meet and interact with more Australian students and other Australians, their interpersonal communication skills in English are likely to improve. In order for this to happen, intervention is required both at the classroom level (that is, in teaching and learning practice) and through other strategies external to the classroom (Briguglio, 2006). Perhaps universities need to to devise different and better support structures to promote the development of listening and speaking skills (Dooey, 2006) supplementary to those support programs which already exist, in many cases, for academic writing.

The 'divide' on campus between international and local students is a problem in all Australian universities that has been well researched and documented (Nesdale \& Todd, 1997; Volet \& Ang, 1998; Smart, Volet \& Ang, 2000; Liddicoat et al., 2003). Unfortunately, its continuation means that universities are not capitalising on the great opportunities for intercultural learning for both Australian and international students (Leask 2003; Briguglio 2006). A recent Australian Learning and Teaching Council (ALTC) project examining ways to promote interaction between international and local students has just been completed and provides a wealth of suggestions (Arkoudis et al., 2010). Finally, there are several myths that are dispelled by this study and which are supported by earlier research. Some commonly held erroneous beliefs about Chinese learners include that they:

- are "passive" learners who do not want to participate in classroom discussion;

- prefer more teacher-directed methods of teaching;

- simply prefer to rote learn content; and

- $\quad$ are not interested in mixing with Australian students.

We have seen from the discussion above that although these Chinese students reported that they had indeed been in a sense more 'passive' and teacher-directed in their previous learning environments, they are open to (and in some cases excited by) different approaches to learning. And although students reported that their previous cramming for exams had been easier, several of them indicated they enjoyed completing assignments and projects and felt that this led to a more satisfying learning experience. Several students also indicated they were proud they had now acquired skills for more independent learning.

We have also seen that students would dearly love to mix more with native speakers, realising that this is one of the sure ways of improving their speaking and listening skills, but also in order to learn more about Australian culture. Unfortunately, their lack of fluency and confidence in interpersonal communication skills may form a barrier to easy mixing and meeting Australian students and 
members of the Australian community more broadly. Universities need to prepare all students for working in multinational groups/teams so that they can learn intercultural communication skills from each other. This evidently does not happen enough in Australian classrooms but there is growing research of how students could be better prepared to draw benefits and learn skills for intercultural interactions in global workplaces (Volet \& Ang, 1998; Volet, 1999; De Vita, 2002; Crosling \& Martin, 2005; Caspersz et al., 2005; Briguglio, 2006; Kimmel \& Volet, 2010).

In order to move towards any real change in these areas, staff development is paramount and should not be overlooked. Moreover, in this context, staff development needs to go well beyond cultural awareness-raising (which is merely a necessary first step) to exploration of cultural differences and experimentation with teaching and learning strategies that are most effective.

\section{Conclusion}

This short-term longitudinal study examined the on-arrival perceptions and experiences of a group of Chinese students and followed their progress through a semester on an Australian university campus. The results show that Chinese students, although experiencing some difficulties due to personal, socio-cultural, linguistic and learning environment factors, on the whole cope well. By the end of semester, most appeared more confident and 'settled'. All were able to reflect on their experiences, to discuss the positive and negative aspects and, more importantly, on reflection were able to adjust their coping strategies. Importantly, all had been successful in passing units of study undertaken during the semester, some with excellent results. Thus the transition of international students from their familiar teaching and learning environments and approaches to the Australian university setting does happen, and although not without substantial effort, in many cases very successfully.

In regard to the broader Australian experience, more needs to be done by universities to ensure that students develop their interpersonal communication skills in English to higher levels, and that they mix more with Australian students and the broader community. This can only happen if, in the first instance, we experiment with teaching and learning approaches, so that English language skills are embedded across the curriculum and two-way learning between international and local students is promoted in classrooms. Secondly, as well as curriculum development and innovation, this requires extra-curricular strategies which focus on promoting mixing with the broader community. Only then can we ensure that students are more satisfied with their Australian sojourn and that they have, indeed, had a truly "Australian experience". There is room for much experimentation and research in these areas and indeed, in longer-term longitudinal studies that follow international students over the course of their whole degree.

\section{References}

Arkoudis, S., Yu, X. Baik, C., Borland, H., Chang, S., Lang, I., Lang, J., Pearce, A. \& Watty, K. (2010) Finding common ground: Enhancing interaction between domestic and international students. Strawberry Hills, NSW: ALTC.

Atkinson, S. \& Abu El Haj, M. (1996) How to do(or not to do) Domain analysis for qualitative public health data. Health Policy and Planning, Vol 11, No 4, pp. 438-442.

Ballard,B. and Clanchy, J. (1997) Teaching international students. Canberra: IDP.

Bandura, A. (1997) Self-efficacy: The exercise of control. New York: Freeman.

Biggs, J. (1996). Western misperceptions of the Confucian heritage learning culture. In D. Watkins \& J. Biggs (Eds.) The Chinese learner: cultural, psychological and contextual influences ( $\mathrm{pp}$ 45-67). CERC \& ACER, Melbourne.

Birrell, B. (2006) 'Implications of low English standards among overseas students at Australian universities', People and Place, 14 (4) pp. 53-64. 
Blomberg, J., Giacomi, J., Mosher, A., \& Swenton-Wall, P. (1993) Ethnographic Field Methods and Their Relation to Design. In D. Dchuler and A. Namioka (Eds.) Participatory Design: Principles and Practices. Erlbaum: New Jersey, 1993.

Bonanno, H. \& Jones, J. 1996. Integrating lifelong learning skills into first year collaborative approaches to curriculum design. In Proceedings for the Improving University Teaching Conference, UK: Nottingham Trent University.

Bretag, T. (2007) 'The emperor's new clothes: Yes there is a link between English language competence and academic standards', People and Place, 15 (1), pp. 13-21.

Briguglio, C. (2000) Language and cultural issues for English as a second/foreign language students, Higher Education in Europe, 25 (3) 425 - 434.

Briguglio, C. (2006).'Can structured intervention improve intercultural communication in multinational student teams?' In S. H Ong, G. Apfelthalter, K. Hansen and N Tapachai (eds), Intercultural Communication competencies in higher education and management, Marshall Cavendish Academic, Singapore.

Briguglio, C. (2007). Assessing writing skills of entry level undergraduate business students to enhance their writing development during tertiary studies, chapter in Enhancing teaching and learning through assessment, ed S. Frankland, Springer, the Netherlands, pp. 16-23.

Briguglio, C. \& Howe, J. (2006). 'Critical perspectives: students' expectations of difficulties they may face in undertaking their degree', Research \& Development in Higher Education, Vol 29, pp. 50 $-56$.

Caspersz, D., Skene, J. \& Wu, M. 2005. Principles and guidelines in managing student teams, Teaching and Learning Forum 2005. Perth: Edith Cowan University.

Chalmers, D. \& Volet, S. (1997) Common misconceptions about students from South-East Asia studying in Australia. Higher Education Research and Development, Vol 16, No 1, pp 87-99.

Chapman, A. \& Pyvis, D. (2006) Quality, identity and practice in offshore university programmes: Issues in the internationalisation of Australian Higher education. Teaching in Higher Education, 11 (2), pp. 233-245.,

Cooper, B. J. (2004) The enigma of the Chinese learner. Accounting Education 13 (30 pp. 289-310.

Crosling, G. \& Wilson, A. 2005. Creating a rich environment: Cooperation between academic support and disciplinary teaching staff. In Proceedings of the LAS Conference, Critiquing and Reflecting, Canberra, 24-25 November 2005.

Crosling, B. \& Martin, K. (2005). Student diversity and collaborative learning: A positive combination for curriculum internationalisation, in E. Manolo and G. Wong-Toi (eds.). Communication skills in university education: The international dimensions. Auckland: Pearson Educational.

Curtin University of Technology (2010) Annual Report 2009. Available at http://about.curtin.edu.au/annual-reports.cfm [Accessed 20 November 2010]

Department of Education, Employment and Workplace Relations - DEEWR, 2010. Higher Education Statistics. Avaialbe at: http://www.deewr.gov.au/HigherEducation/Publications/HEStatistics/Publications/Pages/Stu dents.aspx [Accessed 20 September, 2010]

De Vita, G. 2002b. Does assessed multicultural group work really pull UK students' average down? Assessment and Evaluation in Higher Education 27(2) 153-161.

Dooey, P. (2006) Identifying the listening and speaking needs of international students. Teaching and Learning Forum 2006 Available at:

http://otl.curtin.edu.au/tlf/tlf2006/refereed/dooey.html [Accessed 6 October 2010]

Hutchison, K., Morrigan, L \& Mappin, M., 1997. Inclusive curriculum: information \& resource guide. Melbourne, Victoria University of Technology.

Kennedy, P. Learning cultures and learning styles: myth-understandings about adult (Hong Kong) Chinese learners. International Journal of Lifelong Education, Vol. 21 (5) pp. 430 -445. 
Kimmel, K. \& Volet, S. (2010). University students' perceptions of and attitudes towards culturally diverse group work: does context matter? Journal of Studies in International Education, Vol. 20 (10)pp. 1-25.

Krause, K (2003). Which way from here? Passion, policy and practice in first year higher education, $7^{\text {th }}$ Pacific Rim First Year in Higher Education Conference, Brisbane, 9-122 July 2003.

Krause, K., Hartley, R., James, R \& McInnis, C. (2005). The first year experience in Australian universities: findings from a decade of national studies. Centre for the Study of Higher Education, University of Melbourne: DEST.

Lawrence, J. 2005. Addressing diversity in higher education: Two models for facilitating student engagement and mastery. In Brew, A. \& Asmar, C. (eds) Higher Education in a changing world. Research and Development in Higher Education, 28. Proceedings of the 2005 HERDSA Annual Conference. Sydney, Australia 3 - 6 July.

Lawrence, J. 2005. Addressing diversity in higher education: Two models for facilitating student engagement and mastery. In Brew, A. \& Asmar, C. (eds) Higher Education in a changing world. Research and Development in Higher Education, 28. Proceedings of the 2005 HERDSA Annual Conference. Sydney, Australia 3 - 6 July.

Le Compte, M. D. \& Schensul, J. (1999). Designing and conducting ethnographic research, Altamira Press, Walnut Creek, California.

Le, T. \& Shi, L. (2006) Chinese background students' learning approaches. Paper presented at AARE conference, Adelaide 27 November, 2006. Available at: http://www.aare.edu.au/06pap/abs06.htm [Accessed 11 Octboer2010]

Leask, B. (2003) Venturing into the unknown - a framework and strategies to assist international and Australian students to learn from each other. HERDSA 2003 conference.

Lewthwaite, M. (1996) A study of international surdents' perspectives on cross-cultural adaptation. International Journal for the Avancement of Counselling, Vol 19 pp. 167-185.

Liddicoat, A., Eisenchlas S. \& Trevaskes, S., Eds. (2003). Australian perspectives on internationalising education, Language Australia Ltd., Melbourne.

Marginson, S. (2006) Dynamics of national and global competition in higher education. Higher Education, Vol. 52 (1), pp.1-39.

McInnis, C. \& James, R. (1995) First year on campus. Canberra: AGPS

Millen, D.R. (2000) 'Rapid ethnography: Time deepening strategies for $\mathrm{HCl}$ field research'. Proceedings of the 3rd conference on Designing interactive systems: processes, practices, methods, and techniques New York City. New York: ACM, pp.280-286

Mulligan, D. \& Kirkpatrick, A. (2000) How much do they understand? Lectures, students and comprehension. Higher Education Research and Development, 19(3) 311-335.

Mullins, G., Quintrell, N. \& Hancock, L. (1995) The experience of international and local students at three Australian universities. HERDSA Vol. 14, No. 2, pp. 201-231.

Nesdale, D \& Todd, P. (1997) Promoting international contact between Australian and international university students. Journal of Higher Education Policy and Management 19(1) 61-76.

Nunan, D. (2003) The impact of English as a global language on educational policies and practices in the Asia-Pacific region. TESOL Quarterly, Vo. 37, No. 4, pp. 589-613.

Pantelides,U.,1999. 'Meeting the language needs of tertiary NESB students', The Australian Journal of Language and Literacy, 22 (1), pp. 60-75.

Ramburuth, P. (2001). The internationalisation of Education: implications for student learning and socio-cultural adjustment. Paper presented at the $15^{\text {th }}$ Australian International Education Conference, University of NSW, 25-28 September 2001.

Ransom, L., Larcombe, W. \& Baik, C. (2005) English language needs and support: international ESL students' perceptions and expectations. Language and Learning Skills Unit, University of Melbourne.

Sawir, E. (2005) Language difficulties of international students in Australia: The effects of prior learning experience. International Education Journal, Vol. 6, No. 5, pp. 567-580. 
Smart, D. Volet, S. \& Ang, G. (2000). Fostering social cohesion in universities: Bridging the cultural divide. AEI and DETYA, Canberra.

Sovic, S. (2008) Lost in transition? The international students 'experience project. Creative Learning in Practice, Centre for Excellence in Teaching and Learning, University of the Arts, London. Available at: http://www.arts.ac.uk/docs/ISEP [Accessed 12 November 2008]

Volet, S. \& Ang, G. (1998) Culturally mixed groups on international campuses: an opportunity for intercultural learning, Higher Education Research and Development, Vol. 17(1) pp. 5-23.

Volet, S. (1999) Learning across cultures: appropriateness of knowledge transfer. International Journal of Education Research, 31, pp. 625-643.

Wang, T. \& Shan, X. (2007) A qualitative study on Chinese postgraduate students' learning experiences in Australia, HERDSA conference proceedings, 2007. Available at http://www.herdsa.org.au/?page_id=217\#W [Accessed 11 October 2010]

Watkins, D. \& Biggs, J. (1996) The Chinese learner: cultural, psychological and contextual influences. CERC \& ACER, Melbourne.

Zhang, V. (2010) The international experience: International Chinese students studying in universities in Sydney. University of Technology Sydney and The Institute for Cultural Diversity. 